\title{
Effect of rosiglitazone and ramipril on macrovasculopathy in patients with type 2 diabetes: needs longer treatment and/or higher doses?
}

This article was published in the following Dove Press journal:

Clinical Pharmacology:Advances and Applications

19 April 2010

Number of times this article has been viewed

\author{
Sayeeda Rahman' \\ Aziz AI-Shafi Ismail ${ }^{2}$ \\ Shaiful Bhari Ismail ${ }^{3}$ \\ Nyi Nyi Naing ${ }^{4}$ \\ Abdul Rashid Abdul Rahman ${ }^{5}$ \\ 'Department of Clinical Sciences, \\ School of Life Sciences, University \\ of Bradford, Bradford, UK; \\ ${ }^{2}$ Department of Community Medicine, \\ ${ }^{3}$ Department of Family Medicine, \\ ${ }^{4}$ Unit of Biostatistics and Research \\ Methodology, School of Medical \\ Sciences, Universiti Sains Malaysia, \\ I6I50 Kubang Kerian, Kelantan, \\ Malaysia; ${ }^{5}$ Cyberjaya University \\ College of Medical Sciences 63000 \\ Cyberjaya Malaysia, Malaysia
}

Introduction: The aim of the study is to investigate whether standard doses of rosiglitazone ( $4 \mathrm{mg} /$ daily) and ramipril (5 mg/daily) can reverse pre-clinical macrovasculopathy in newly diagnosed never treated type 2 diabetes (T2DM) patients.

Methods: In this randomized, double-blind, placebo-controlled study, 33 T2DM patients were randomized to rosiglitazone ( $4 \mathrm{mg} /$ daily) or ramipril ( $5 \mathrm{mg} /$ daily) or placebo for 1 year. Hemodynamic variables were measured at 3 treatment phases and pulse wave velocity (PWV) and augmentation index (AI) were measured throughout the treatment period.

Result: In diabetic patients, PWV $(P=0.037)$ and AI $(P=0.005)$ with ramipril and AI $(P<0.001)$ with rosiglitazone were significantly reduced during overall treatment period from the baseline; however, these differences were not significant in comparison to placebo.

Discussion and conclusion: The present study showed that treatment with standard doses of rosiglitazone and ramipril are not adequate to reverse pre-clinical vasculopathy in T2DM. The lack of benefit in newly diagnosed T2DM may be because of the relatively short-term intervention and/or the use of lower doses of rosiglitazone/ramipril. Further trials are needed for a longer period of time, possibly with higher doses, to show whether rosiglitazone/ramipril can reverse pre-clinical vasculopathy in T2DM (ClinicalTrials.gov number, NCT00489229).

Keywords: rosiglitazone, ramipril, diabetic vasculopathy

Patients with type 2 diabetes (T2DM) have an increased risk of macrovascular complications compared with the general population. ${ }^{1}$ Diabetic macrovascular disease is the commonest cause of morbidity and mortality and is responsible for high incidence of vascular diseases such as stroke, myocardial infarction and peripheral vascular diseases. ${ }^{2}$ In macrovascular diseases, pathophysiological changes in the arterial wall lead to structural and functional changes in the large arteries which cause increased stiffness, abnormal pulse wave travel and increased systolic hypertension. Diabetes complications can be controlled and avoided by strict glycemic control, maintaining normal lipid profiles, regular physical exercise, adopting a healthy lifestyle and pharmacological interventions. Treatment goals for T2DM specify targets for glycemia and other cardiometabolic risk factors, eg, hypertension and dyslipidemia. In recent years, special interest has been developed in the use of thiazolidinediones (TZDs) (eg, rosiglitazone, ${ }^{3,4}$ piolitazone ${ }^{5,6}$ ) and angiotensin converting enzyme (ACE) inhibitors (eg, ramipril, ${ }^{7}$ enalapril, ${ }^{8,9}$ perindopril ${ }^{10}$ ) to treat diabetic macrovasculopathy. To date, a few studies had been conducted on T2DM to investigate the pharmacological
Correspondence: Sayeeda Rahman Department of Clinical Sciences, School of Life Sciences, University of Bradford, Bradford BD7 IDP, UK

Tel +44 I 274236283

Emailsrahman6@bradford.ac.uk, seempi2005@yahoo.co.uk 
actions of rosiglitazone $e^{3,4}$ and ramipril ${ }^{7}$ on arterial stiffness. The aim of our study was to investigate whether standard doses of rosiglitazone and ramipril can reverse pre-clinical macrovasculopathy in newly diagnosed never treated T2DM patients.

\section{Methods}

\section{Subjects}

A preliminary screening of 1620 subjects was conducted in hospital and other community-settings from October 2002 to October 2004. ${ }^{11,12}$ Participants were 30 to 65 years of age, newly diagnosed never treated (no antidiabetic, antihypertensive, lipid lowering agents or any other medication) T2DM patients, non-obese (BMI $<30 \mathrm{~kg} / \mathrm{m}^{2}$ ), non-smoker, nonhyperlipidemic (total cholesterol $<7.8 \mathrm{mmol} / \mathrm{L}$ ), no previous history of micro- and macrovascular complications, and no atrial fibrillation. Known diabetic and hypertensive cases were excluded. Out of 1620, 644 met the study criteria and had oral glucose tolerance test (OGTT). Thirty-three patients were included who met the study criteria. The research protocol was approved by the research and ethics committee of Universiti Sains Malaysia.

\section{Research strategy}

\section{Randomization}

The patients were randomized into 3 treatment groups (11 in each group) and randomly assigned to either rosiglitazone (4 mg), or ramipril (5 mg), or placebo. The treatment assignment was randomly distributed among each group of patients by block randomization. The process of randomization was carried out between 2002 and 2005.

\section{Measurement and follow up}

Total follow up period was 1 year, comprising 9 visits -1 st (week 1, week 2, week 4), 3rd, 5th, 7th, 9th, 11th and 12 th month. The follow-up of all the patients was completed by 2005 . Hemodynamic variables were measured at 3 treatment phases (1st [week 1], 7th and 12th month) and arterial stiffness was measured at every visit. Arterial stiffness (pulse wave velocity [PWV] and augmentation index [AI]) was assessed by SphygmoCor ${ }^{\circledR}$ (PWV Medical Pty. Australia) and details were described elsewhere. ${ }^{11,12}$ The power to demonstrate the differences in arterial stiffness between groups was at $80 \%$ and alpha of 0.05 (2 tailed) and the coefficient of variance for PWV was $3.12 \mathrm{~m} / \mathrm{s}$ and for AI $2.93 \%$.

\section{Data analysis}

Statistical analysis was performed using SPSS for windows (version 11.5). Data are expressed as mean \pm standard deviation. Repeated measure analysis of variance was applied to determine the between group changes of PWV and AI at 1st (week 1, week 2, week 4), 3rd, 5th, 7th, 9th, 11 th and 12 th month after drugs were started. Within group changes were analyzed by using multiple paired $t$-test method. Week 1 (month 1) was considered as the baseline of the study. $P$ value was compared with the $\alpha$-Bonferroni correction, which was found to be 0.0013 . Test results for treatment group effects were considered significant as $P$ value $<0.05$.

\section{Results}

Among diabetes subjects, a total of $10(91 \%)$ in the rosiglitazone, $11(100 \%)$ in ramipril and $10(91 \%)$ in placebo group completed the study. In diabetic patients, PWV $(P=0.037)$ and AI $(P=0.005)$ with ramipril and AI $(P<0.001)$ with rosiglitazone were significantly reduced during overall treatment period from the baseline (Figure 1); however, these differences were not significant in comparison to placebo (Table 1). A significant decrease in 2-hour postprandial glucose $(P<0.001)$ and total cholesterol $(P=0.025)$ and significant increase in low-density lipoprotein (LDL) (at month 7, $P=0.02$ ) were demonstrated within rosiglitazone treatment group from the baseline. Ramipril group showed significant reduction in 2-hour postprandial glucose $(P=0.007)$ and LDL $(P=0.011)$ throughout study period; however, these changes were not significant in comparison to placebo (Table 1).

The use of standard doses of rosiglitazone ( $4 \mathrm{mg} /$ day) and ramipril ( $5 \mathrm{mg}$ /day) were found to have less serious side-effects. There was a small weight gain $(0.43 \%$ from baseline) in T2DM patients with rosiglitazone treatment but it was not statistically significant compared to placebo. Six diabetic patients had average of $1.75 \mathrm{~kg}$ weight gain with rosiglitazone. Most importantly, no patient suffered from myocardial infraction, congestive cardiac failure or died due to cardiovascular causes in this group as reported in a published meta-analysis. ${ }^{13}$ This may be due to the absence of any cardiovascular diseases/risk factors in this particular patient group who were much younger (47 years), drug naïve and newly diagnosed diabetic patients. One patient experienced mild cough (tolerable irritation) with ramipril during treatment period; however, the symptom subsided without any treatment. 

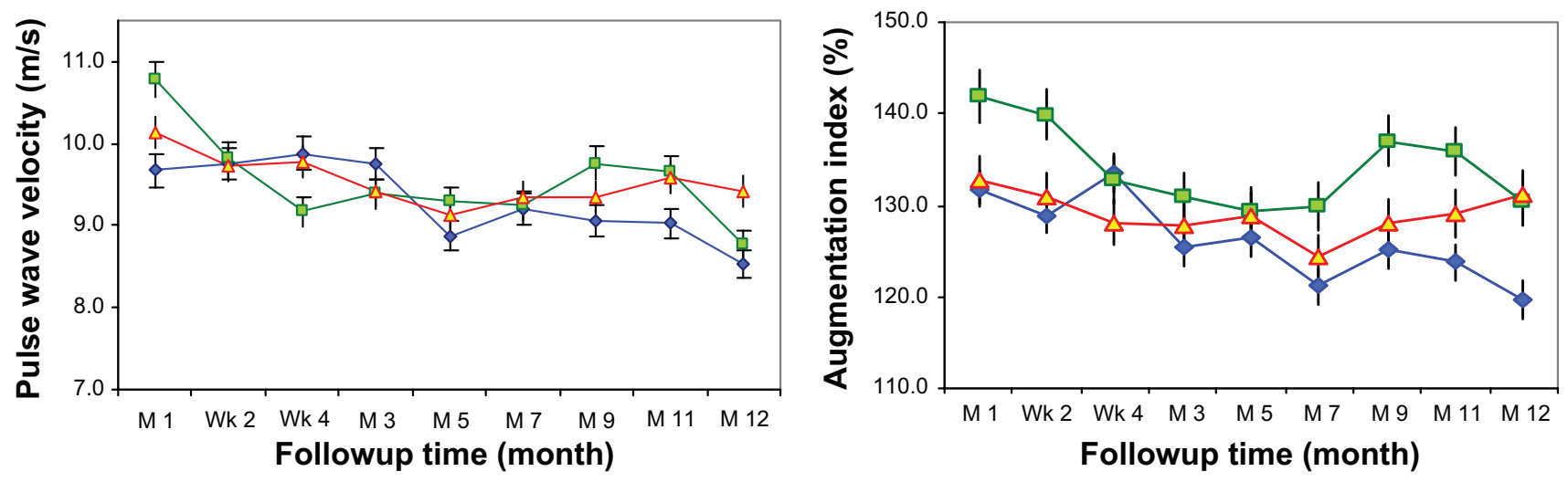

$$
\multimap \text { Rosiglitazone } \multimap-\text { Ramipril } \longleftarrow \text { Placebo }
$$

Figure I Estimated marginal means of PWV and $\mathrm{Al}$ in type 2 diabetes between treatment with rosiglitazone, ramipril and placebo from base line overtime.With ramipril PWV $(P=0.037)$ and $\mathrm{Al}(P=0.005)$ and with rosiglitazone $\mathrm{Al}(P<0.00 \mathrm{I})$ were significantly reduced during overall treatment period from the baseline.

Abbreviations: $\mathrm{Al}$, augmentation index; $\mathrm{PWV}$, pulse wave velocity.

\section{Discussion and conclusion}

The present study is the first to investigate the effect of rosiglitazone and ramipril on arterial stiffness in newly diagnosed never treated T2DM patients without any cardiovascular (CV) complication using strict inclusion and exclusion criteria. Although the treatments showed a significant change in preclinical vasculopathy from the baseline, but could not find any difference in comparison to placebo. The main reason why diabetic patients failed to show any changes may be due to shorter duration of intervention ${ }^{3,8,10}$ and/or lower dose of the drugs. ${ }^{14}$ The much-developed vasculopathy in established diabetes may need intervention for a longer period of time $\mathrm{e}^{7,15}$ and/or the use of higher doses of rosiglitazone $(8 \mathrm{mg})^{16}$ and ramipril (10 mg). ${ }^{7,15}$

The rationale of using standard dose of rosiglitazone $4 \mathrm{mg}$ /day was found to be effective in controlling biochemical

Table I Changes in hemodynamic and biochemical parameters following treatment in type 2 diabetes

\begin{tabular}{|c|c|c|c|c|c|c|}
\hline \multirow[t]{2}{*}{ Parameters } & \multicolumn{2}{|c|}{ Rosiglitazone } & \multicolumn{2}{|l|}{ Ramipril } & \multicolumn{2}{|l|}{ Placebo } \\
\hline & Baseline & Treated & Baseline & Treated & Baseline & Treated \\
\hline BMI $\left(\mathrm{kg} / \mathrm{m}^{2}\right)$ & $26.6 \pm 1.4$ & $26.8 \pm 1.2$ & $26.7 \pm 4.3$ & $26.1 \pm 4.4$ & $27.0 \pm 3.2$ & $27.0 \pm 3.3$ \\
\hline $\mathrm{SBP}(\mathrm{mmHg})$ & $126.6 \pm 9.2$ & $125.1 \pm 9.9$ & $123.1 \pm 11.4$ & $116.5 \pm 14.8$ & $130.5 \pm 6.2$ & $120.6 \pm 10.9$ \\
\hline $\mathrm{DBP}(\mathrm{mmHg})$ & $77.0 \pm 6.9$ & $74.8 \pm 9.1$ & $75.6 \pm 6.0$ & $69.0 \pm 9.1$ & $80.4 \pm 6.8$ & $75.8 \pm 6.4$ \\
\hline HR (bpm) & $67.7 \pm 16.4$ & $70.4 \pm 9.0$ & $66.6 \pm 7.8$ & $68.1 \pm 8.5$ & $70.5 \pm 11.6$ & $71.9 \pm 10.5$ \\
\hline FBS (mmol/L) & $8.4 \pm 3.4$ & $6.8 \pm 1.9$ & $8.6 \pm 3.0$ & $7.4 \pm 2.5$ & $9.2 \pm 3.7$ & $7.9 \pm 2.1$ \\
\hline $2 \mathrm{hPPG}(\mathrm{mmol} / \mathrm{L})$ & $14.6 \pm 3.6$ & $9.8 \pm 3.7^{*}$ & $14.6 \pm 5.1$ & $11.9 \pm 5.3^{* *}$ & $15.4 \pm 4.8$ & $14.0 \pm 2.8$ \\
\hline $\mathrm{HbA}_{\mathrm{Ic}}(\%)$ & $7.5 \pm 1.7$ & $6.3 \pm 2.6$ & $7.3 \pm 2.1$ & $6.7 \pm 1.5$ & $8.3 \pm 2.3$ & $7.1 \pm 1.3$ \\
\hline $\mathrm{Fl}$ (ulU/mL) & $10.6 \pm 5.6$ & $9.6 \pm 5.1$ & $9.3 \pm 5.0$ & $9.1 \pm 4.7$ & $7.6 \pm 3.3$ & $7.5 \pm 2.9$ \\
\hline $\mathrm{HDL}$ (mmol/L) & $1.4 \pm 0.4$ & $1.5 \pm 0.6$ & $1.3 \pm 0.1$ & $1.3 \pm 0.2$ & $1.3 \pm 0.3$ & $1.2 \pm 0.2$ \\
\hline $\mathrm{LDL}(\mathrm{mmol} / \mathrm{L})$ & $3.6 \pm 0.6$ & $4.0 \pm 0.6^{*}$ & $4.0 \pm 1.2$ & $3.1 \pm 1.0^{*}$ & $3.7 \pm 1.4$ & $3.9 \pm 1.0$ \\
\hline $\mathrm{TG}(\mathrm{mmol} / \mathrm{L})$ & $1.8 \pm 0.8$ & $1.5 \pm 1.1$ & $1.3 \pm 0.5$ & $1.2 \pm 0.7$ & $1.8 \pm 0.9$ & $2.0 \pm 0.9$ \\
\hline TChol (mmol/L) & $5.9 \pm 0.9$ & $5.4 \pm 1 . I^{* *}$ & $5.8 \pm 0.8$ & $5.5 \pm 0.8$ & $5.9 \pm 1.4$ & $6.5 \pm 3.1$ \\
\hline $\mathrm{Al}(\%)$ & $131.7 \pm 18.9$ & $119.6 \pm 13.9 *$ & $|4| .9 \pm 17.8$ & $130.3 \pm 13.9 * *$ & $132.8 \pm 15.0$ & $131.1 \pm 11.7$ \\
\hline $\mathrm{PWV}(\mathrm{m} / \mathrm{s})$ & $9.6 \pm 2.2$ & $8.5 \pm 0.9$ & $10.7 \pm 3.5$ & $8.7 \pm 1.6^{*}$ & $10.1 \pm 1.9$ & $9.4 \pm 2.1$ \\
\hline
\end{tabular}

Notes: Values are means \pm standard deviation (SD); $P$ values are based on analysis of variance (ANOVA). $* P<0.001, * * P<0.05$.

Abbreviations: Al, augmentation index; BMI, body mass index; SBP, systolic blood pressure; DBP, diastolic blood pressure; HR, heart rate; FBS, fasting blood sugar; 2hPPG, 2-h postprandial glucose; HbA , glycated hemoglobin; Fl, fasting insulin; HDL, high-density lipoprotein; LDL, low-density lipoprotein; TG, triglyceride; TChol, total cholesterol; PWV, pulse wave velocity. 
parameters of diabetes in most of the previous clinical trials. ${ }^{17,18}$ Thiazolidinediones are found to be most effective when used with the earliest form of diabetes and also in the drug naïve patients when insulin secretion is still substantial. ${ }^{19-21}$ Phillips et al ${ }^{17}$ recommend that once-daily dose (4 mg) may be sufficient as first-line therapy for patients with recent diagnoses, and $4 \mathrm{mg}$ twice daily for patients with more advanced diabetes. Our study demonstrated a clear trend of decreasing PWV, AI and other hemodynamics variables throughout the study period (significant with baseline, Table 1), though the changes were not significant in comparison to placebo. The reason of insignificant improvement may be that large arteries have a major component of fixed fibrotic tissue which probably needs more time for 'tissue repair' in much developed vasculopathy in patients with T2DM. ${ }^{3}$ Shargorodsky et $\mathrm{al}^{3}$ increased the dose from $4 \mathrm{mg} /$ daily dose to $8 \mathrm{mg} /$ daily after 3 -month treatment in patients who had hemoglobin $\mathrm{A}_{1 \mathrm{c}}$ level $>9 \%$ and continued for further 3 months. However, they failed to show any changes in large artery stiffness in T2DM with increased dose. Pistrosch et $\mathrm{al}^{4}$ demonstrated that rosiglitazone (4 mg twice daily) had therapeutic effects on endothelial dysfunction in T2DM $(n=12)$ patients in a 12-week double blind cross-over study. From this evidence, it may be suggested that higher dose of rosiglitazone is needed for longer duration to reverse the preclinical macrovasculopathy.

The present study is the first to conduct a clinical trial with standard dose of ramipril ( $5 \mathrm{mg}$ daily) to examine its effects on arterial stiffness. Previous studies used $1.25 \mathrm{mg} /$ day, ${ }^{14}$ $2.5 \mathrm{mg} /$ day $^{7}$ or $10 \mathrm{mg} /$ day $^{7}$ to study the cardioprotective effects in patients with T2DM. However, $1.25 \mathrm{mg} /$ day and $2.5 \mathrm{mg} /$ day failed to show any effect on CV outcomes. The SECURE study also showed a strong dose dependency of atherosclerosis progression, with highest benefit in the ramipril $10 \mathrm{mg} /$ day study group than $2.5 \mathrm{mg} /$ day group. ${ }^{7}$ Ramipril $10 \mathrm{mg} /$ day was also the dose used in the HOPE trial, where it had very clear benefits on a range of clinical end points. The absence of $\mathrm{CV}$ protection with standard dose of ramipril in our study may suggest that a higher dose is required to reverse the macrovasculopathy in diabetes patients.

The present study is also the first to conduct a clinical trial with 1-year duration to examine the effects of ramipril on diabetic vasculopathy. Previous short-term studies (12 week to 6 months) on diabetes ${ }^{8,10}$ and hypertensive patients ${ }^{22,23}$ investigated effectiveness of ACE inhibitors on arterial stiffness could not definitively establish therapeutic efficacy. In a recent study, Kaiser et $\mathrm{al}^{8}$ compared the effects of a $\beta$-blocker (nebivolol) with an ACE inhibitor (enalapril) on parameters of insulin sensitivity, peripheral blood flow and arterial stiffness in T2DM patients assessing PWV and AI using SphygmoCor. No differences between nebivolol and enalapril were observed on any of above mentioned parameters. The authors suggested larger scale clinical trials with a longer treatment duration to investigate hard clinical endpoints in hypertensive T2DM patients. Another study ${ }^{24}$ examined the effect of angiotensin-converting enzyme (ACE) inhibitors (perindopril) on arterial stiffness for 7 months and suggested that high doses of ACE inhibitors, administered for a long period of time, are required in hypertensive T2DM patients to obtain a marked inhibition of the renin-angiotensin system and to reduce carotid stiffness.

In contrast, long-term studies ${ }^{7,9,15}$ established cardioprotective effects of ramipril in patients with T2DM. The SECURE, and MICRO-HOPE studies conducted for 4.5 years showed clear benefits of ramipril on $\mathrm{CV}$ end points. Bosch et $\mathrm{al}^{25}$ reported that prolonged use of ramipril prevents incidence of stroke in patients with vascular diseases and diabetes, followed for 4.5 years as part of the HOPE study. A study conducted by Hosomi et $\mathrm{al}^{9}$ demonstrated longterm treatment (2 years) with an ACE inhibitor (enalapril) and confirmed that 'age-related' and 'diabetic-associated' atherosclerosis was slowed down by chronic treatment for a period of 2 years. In their study systolic blood pressure (SBP) decreased on average by $4.8 \mathrm{mmHg}$ during the first year and was maintained at the same level during the second year. The author speculated that decreased SBP during the first period may slightly constrict the common carotid artery and may transiently increase the apparent intima-media thickness (IMT), which may in turn decrease the wall tension and eventually slow the rate of IM thickening. It is suggested that a minimum 2-year treatment period is needed to evaluate therapeutic efficacy on IMT and to exclude possible early (up to 1 year) confounding of transient or apparent effects due to decreased SBP. Intra-group analysis in our study showed mean reduction of $6.64 \mathrm{mmHg}$ in SBP in T2DM patients and this suggests long-term treatment ( $>2$ years) with ramipril to demonstrate significant improvement in arterial stiffness.

Considering all this evidence, it can be emphasized that treatment with ramipril needs higher doses (10 $\mathrm{mg}$ or more) and longer treatment ( $>2$ years) and this is confirmed by SECURE and DIABHYCAR studies. The SECURE study showed improvement of arterial stiffness with higher doses $(10 \mathrm{mg} /$ day, not with $2.5 \mathrm{mg} /$ day) for a treatment of 4.5 years and on the other hand DIABHYCAR study failed to show any improvement with $1.25 \mathrm{mg} /$ day for a period of 2.5 years. 
As the studies with rosiglitazone and ramipril on arterial stiffness are very limited, further randomized controlled trials should be undertaken for a longer period of time, possibly with higher doses, to show whether rosiglitazone and ramipril can reverse pre-clinical macrovasculopathy in T2DM.

\section{Acknowledgments}

We are grateful to the Ministry of Science and Technology and Environment, the Government of Malaysia for supporting this project [IRPA (Intensification of Research in Priority Areas) Grant no. 305/PPSP/6112215].

\section{Disclosures}

The authors report no conflict of interest.

\section{References}

1. Stamler J, Vaccaro O, Neaton JD, Wentworth D. Diabetes, other risk factors, and 12-yr cardiovascular mortality for men screened in the multiple risk factor intervention trial. Diabetes Care. 1993;16(2):434-444.

2. Rahman S, Rahman T, Ismail AA, Rahman ARA. Diabetes-associated macrovasculopathy: pathophysiology and pathogenesis. Diab Obes Metab. 2007;9(6):767-780.

3. Shargorodsky S, Wainstein G, Gavish E, Leibovitz Z, Matas D, Zimlichman R. Treatment with rosiglitazone reduces hyperinsulinemia and improves arterial elasticity in patients with type 2 diabetes mellitus. Am J Hyperten. 2003;16(8):617-622.

4. Pistrosch F, Passauer J, Fischer S, Fuecker K, Hanefeld M, Gross P. In Type 2 diabetes rosiglitazone therapy for insulin resistance ameliorates endothelial dysfunction independent of glucose control. Diabetes Care. 2004;27(2):484-490.

5. Langenfeld MR, Forst T, Hohberg C, et al. Pioglitazone decreases carotid intima-media thickness independently of glycemic control in patients with type 2 diabetes: Results from a controlled randomized study. Circulation. 2005;111(19):2525-2531.

6. Watanabe I, Tani S, Anazawa T, Kushiro T, Kanmatsuse K. Effect of pioglitazone on arteriosclerosis in comparison with that of glibenclamide. Diabetes Res Clin Pract. 2005;68(2):104-110.

7. Lonn E, Yusuf S, Dzavik V, et al. Effects of ramipril and vitamin E on atherosclerosis: the study to evaluate carotid ultrasound changes in patients with ramipril and vitamin E (SECURE). Circulation. 2001;103(7):919-925.

8. Kaiser T, Heise T, Nosek L, Eckers U, Sawicki PT. Influence of nebivolol and enalapril on metabolic parameters and arterial stiffness in hypertensive type 2 diabetic patients. J Hypertens. 2006;24(7):1397-1403.

9. Hosomi N, Mizushige K, Ohyama H, et al. Angiotensin-converting enzyme inhibition with enalapril slows progressive intima-media thickening of the common carotid artery in patients with non-insulin-dependent diabetes mellitus. Stroke. 2001;32(7):1539-1545.

10. Manolis AJ, Iraklianou S, Pittaras A, et al. Arterial compliance changes in diabetic normotensive patients after angiotensin converting enzyme inhibition therapy. Am J Hypertens. 2005;18(1):18-22.

Clinical Pharmacology: Advances and Applications

\section{Publish your work in this journal}

Clinical Pharmacology: Advances and Applications is an international, peer-reviewed, open access journal publishing original research, reports, reviews and commentaries on all areas of drug experience in humans. The manuscript management system is completely online and includes a very quick and fair peer-review system, which is all easy to use.
11. Rahman $\mathrm{S}$, Rahman $\mathrm{T}$, Ismail AA, Ismail SB, Naing NN, Rahman ARA. Effect of Rosiglitazone and ramipril on preclinical vasculopathy in newly diagnosed, untreated T2DM and IGT patients: one-year randomised, double-blind and placebo-controlled study. Eur J Clin Pharmacol. 2007;63(8):733-741.

12. Rahman S, Rahman T, Ismail AA, Ismail SB, Naing NN, Rahman ARA. Early manifestation of macrovasculopathy in newly diagnosed never treated type II diabetic patients with no traditional CVD risk factors. Diabetes Res Clin Pract. 2008;80(2):253-258.

13. Nissen SE, Wolski K. Effect of rosiglitazone on the risk of myocardial infarction and death from cardiovascular causes. $N$ Engl J Med. 2007;356(24):2457-2471.

14. Marre M, Lievre M, Chatellier G, Mann JFE, Passa P, Ménard J. Effects of low dose ramipril on cardiovascular and renal outcomes in patients with type 2 diabetes and raised excretion of urinary albumin: randomised, double blind, placebo controlled trial (the DIABHYCAR study). BMJ. 2004;328(7438):495-499.

15. HOPE Study Investigators: Effects of ramipril on cardiovascular and microvascular outcomes in people with diabetes mellitus: result of HOPE study and MICRO-HOPE substudy. Lancet. 2000;355(9200):253-259.

16. American diabetic association: standards of medical care for patients with diabetes mellitus (position statement). Diabetes Care. 1998;21(Suppl 1):s23-s31.

17. Philips LS, Grunberger G, Miller E, Patwardham R, Rappaport EB, Salzman A. Once- and twice daily dosing of rosiglitazone improves glycemic control in patients with type 2 diabetes. Diabetes Care. 2001;24(2):308-315.

18. Haffner SM, Greenberg AS, Weston WM, Chen H, Williams K, Freed MI. Effect of Rosiglitazone Treatment on Nontraditional Markers of Cardiovascular Disease in Patients with Type 2 Diabetes Mellitus. Circulation. 2002;106(6):679-684.

19. Fonseca VA, Valiquett TR, Huang SM, Ghazzi MN, Whitcomb RW. Troglitazone monotherapy improves glycemic control in patients with type 2 diabetes mellitus: a randomized, controlled study. The Troglitazone Study Group. J Clin Endocrinol Metab. 1998;83(9): 3169-3176.

20. Aronoff S, Rosenblatt S, Braithwaite S. Pioglitazone hydrochloride monotherapy improves glycemic control in the treatment of patients with type 2 diabetes: a 6-month randomized placebo-controlled doseresponse study. The Pioglitazone 001 Study Group. Diabetes Care. 2000;23(11):1605-1611.

21. Silvio E, Inzucchi MD. Oral anti hyperglycemic therapy for type 2 diabetes scientific review. JAMA. 2002;287(3):360-372.

22. Girerd X, Giannattasio C, Moulin C, Safar M, Mancia G, Laurent S. Regression of radial artery wall hypertrophy and improvement of carotid artery compliance after long-term antihypertensive treatment in elderly patients. J Am Coll Cardiol. 1998;31(5):1064-1073.

23. Roman, MJ, Alderman MH, Pickering TG, et al. Differential effects of angiotensin converting enzyme inhibition and diuretic therapy on reductions in ambulatory blood pressure, left ventricular mass, and vascular hypertrophy. Am J Hypertens. 1998;11(4):387-396.

24. Tropeano AI, Boutouyrie P, Pannier B, et al. Brachial pressureindependent reduction in carotid stiffness after long-term angiotensinconverting enzyme inhibition in diabetic hypertensives. Hypertension. 2006;48(1):80-86.

25. Bosch J, Yusuf S, Pogue J, et al. Use of ramipril in preventing stroke: double blind randomised trial. BMJ. 2002;324(7339):699-702.

\section{Dovepress}

Visit http://www.dovepress.com/testimonials.php to read real quotes from published authors. 